\title{
Grupos funcionais de gramíneas forrageiras tropicais ${ }^{1}$
}

\author{
Carlindo Santos Rodrigues ${ }^{2}$, Domicio do Nascimento Júnior ${ }^{3}$, Edenio Detmann ${ }^{3}$, Sila \\ Carneiro da Silva ${ }^{5}$, Braulio Maia de Lana Sousa ${ }^{3}$, Márcia Cristina Teixeira da Silveira ${ }^{4}$
}

\author{
1 Financiado pelo CNPq. \\ 2 Instituto Federal de Educação, Ciências e Tecnologia Baiano - IF BAIANO - Núcleo de Ciências Agrárias, Campus Uruçuca, BA - Brasil. \\ ${ }^{3}$ Universidade Federal de Viçosa - UFV - Departamento de Zootecnia, Viçosa, MG - Brasil. \\ ${ }^{4}$ Embrapa Pecuária Sul, CPPSUL - Embrapa Sul, Bagé, RS - Brasil. \\ ${ }^{5}$ Escola Superior de Agricultura Luiz de Queiroz - Esalq - Departamento de Zootecnia, Piracicaba, SP-Brasil.
}

RESUMO - Foram avaliadas as características morfogênicas e estruturais de gramíneas forrageiras com o objetivo de agrupá-las, de acordo com seu padrão de desenvolvimento, em seus respectivos grupos funcionais. As gramíneas foram plantadas em parcelas de $1,0 \mathrm{~m}^{2}$ com 24 plantas, em delineamento de blocos completos casualizados com três repetições. Os dados foram submetidos à análise de fatores, reduzindo as variáveis em quatro fatores: desenvolvimento de massa, mortalidade de perfilhos, estádio de desenvolvimento e longevidade foliar. Os dados foram submetidos à análise de agrupamento por otimização de Tocher adotando-se a distância euclidiana média como medida básica de dissimilaridade. As gramíneas foram agrupadas da seguinte forma: Verão - grupo I (Xaraés, Massai, Mombaça e Marandu); grupo II (Gordura e Aruana); e grupo III (Jaraguá). Outono grupo I (Mombaça, Massai, Xaraés, Marandu e Gordura); grupo II - (Jaraguá); e grupo III (Aruana). Possivelmente a maior participação do fator mortalidade de perfilhos na formação dos grupos no período de outono influenciou na reorganização dos grupos. Os padrões de desenvolvimento de massa dos diferentes grupos de gramíneas diferiram entre si quanto à forma de utilização dos recursos disponíveis. Houve mudança nos escores de todos os fatores com a mudança do período do verão para o outono. O agrupamento funcional comprova que gramíneas de gêneros e/ou espécies diferentes podem ser enquadradas em um mesmo grupo.

Palavras-chave: análise multivariada, avaliação de gramíneas, características estruturais, morfogênese

\section{Functional clusters of tropical forage grasses}

\begin{abstract}
Morphogenetic and structural characteristics of forage grasses were evaluated in order to group them according to their pattern of development in their respective functional groups. Grasses were planted in plots of $1.0 \mathrm{~m}^{2}$ with 24 plants in a completely randomized block design with three replications. Data were submitted to factor analysis, reducing the variables to four factors: mass development, tiller mortality, developmental stage and leaf longevity. The data were submitted to cluster analysis by Tocher's optimization by adopting the mean Euclidean distance as a basic measure of dissimilarity. Grasses were grouped as follows: Summer - the group I (Xaraés, Massai, Mombaca and Marandu); group II (Molassa and Aruana); and group III (Jaraguagrass). Fall - group I (Mombaca, Massai, Xaraés, Marandu and Molassa); group II (Jaraguagrass); and group III (Aruana). Possibly, the greater role of the tiller mortality factor in the formation of groups in the fall influenced the reorganization of the groups. The patterns of mass development of the different groups of grasses differ from each other as for the means of utilizing the resources available. There was a change in the scores of all factors with the change of the period from summer to Fall. The functional clustering of grasses demonstrates that gender and/or different species can be placed in the same group.
\end{abstract}

Key Words: evaluation of grasses, morphogenesis, multivariate analysis, structural characteristics

\section{Introdução}

A falta de informações técnicas consistentes e confiáveis sobre as gramíneas forrageiras tropicais tem sido a causa das recomendações de práticas de manejo muitas vezes inadequadas e inconsistentes com seu padrão de crescimento e desenvolvimento, culminando na ineficiência do processo de colheita. A avaliação do padrão de crescimento e desenvolvimento de plantas forrageiras constitui importante estratégia, tanto para a caracterização do potencial de produção quanto para a definição do potencial de uso de determinado ecossistema para a produção animal (Nascimento Júnior et al., 2002). Assim, a compreensão dos processos morfofisiológicos e de sua 
interação com o ambiente é fundamental para o entendimento dos mecanismos de como funciona a planta forrageira, tanto a curto quanto a longo prazo.

Pelo estudo da morfogênese, é possível descrever os processos de crescimento, adaptação ecológica e dinâmica do acúmulo de forragem de determinada espécie, contribuindo para o planejamento, a adoção de práticas de manejo eficientes e adequadas a cada tipo de planta forrageira. Outra forma de inferir sobre o padrão de desenvolvimento das gramíneas é por intermédio da formação de grupos funcionais (Silveira et al., 2010).

A formação de grupos funcionais alicerçada no método estatístico Multivariado, por intermédio da análise de grupos (cluster analysis), permite a classificação dos indivíduos estudados de acordo com a similaridade existente (Dias-Filho et al., 1994). Na literatura podem ser observados diversos exemplos do uso da análise de grupos aplicados a análise agronômica e estudos com reprodução de plantas (Murphy et al., 1986; Jolliffe et al., 1989; Brown, 1991; Dias-Filho et al., 1992, 1994; White, 1993; Silveira et al., 2010).

A ideia de grupo funcional, associada às características morfogênicas e estruturais, permite ao pesquisador melhor compreensão do desenvolvimento das plantas. Isso possibilitaria melhor planejamento do processo de avaliação e redução no tempo de experimentação no campo, uma vez que as plantas já poderiam ser avaliadas sob condições de manejo muito próximas daquilo que seria o indicado para elas. Assim, este trabalho foi conduzido com o objetivo de enquadrar as gramíneas avaliadas em grupos funcionais baseados em padrões específicos de desenvolvimento e determinados por meio das características morfogênicas e estruturais das plantas.

\section{Material e Métodos}

O experimento foi conduzido no setor de Forragicultura do Departamento de Zootecnia da Universidade Federal de Viçosa, em Viçosa, Minas Gerais, no período de novembro de 2006 a maio de 2007. As coordenadas geográficas aproximadas são $20^{\circ} 45^{\prime} \mathrm{S}$ de latitude, $42^{\circ} 51^{\prime} \mathrm{W}$ de longitude e 651 m de altitude. Segundo a classificação de Köppen, o clima é do tipo Cwa, subtropical, apresentando estações seca (nos meses de maio a outubro) e chuvosa (nos meses de novembro a abril). Informações referentes às condições climáticas, como precipitação, temperaturas máximas, médias e mínimas durante o período experimental (Figura 1) foram obtidas na Estação Meteorológica da UFV, a cerca de $1.000 \mathrm{~m}$ do local do experimento.
O solo local é classificado como Argissolo VermelhoAmarelo, com textura franco-argilosa (EMBRAPA, 2006). Amostras de solo foram retiradas na camada de 0 a $20 \mathrm{~cm}$ e encaminhadas para avaliação, cujas características químicas médias da área experimental eram: $\mathrm{pH}$ em $\mathrm{H}_{2} \mathrm{O}=5,5 ; \mathrm{Ca}=$ $2,1 \mathrm{cmol}_{\mathrm{C}} \mathrm{dm}^{-3} ; \mathrm{Mg}=0,7 \mathrm{cmol}_{\mathrm{C}} \mathrm{dm}^{-3} ; \mathrm{P}=1,4 \mathrm{mg} \mathrm{dm}^{-3} ; \mathrm{K}=$ $36 \mathrm{mg} \mathrm{dm}^{-3} ; \mathrm{Al}=0,0 \mathrm{cmol}_{\mathrm{C}} \mathrm{dm}^{-3} ; \mathrm{H}+\mathrm{Al}=4,3 \mathrm{cmol}_{c} \mathrm{dm}^{-3} ; \mathrm{CTC}$ $(\mathrm{T})=7,2 \mathrm{cmol}_{\mathrm{C}} \mathrm{dm}^{-3} ; \mathrm{CTC}(\mathrm{t})=2,9 \mathrm{cmol}_{\mathrm{C}} \mathrm{dm}^{-3} ; \mathrm{V}=40 \%$. A área utilizada passou por processos de correção em experimentos anteriores, não sendo detectada a presença de alumínio trocável. Os valores de $\mathrm{pH}$ encontravam-se dentro da faixa considerada satisfatória para a implantação das gramíneas em estudo (CFSEMG, 1999). Foi realizada a adubação de formação de $100 \mathrm{~kg} \mathrm{ha}^{-1}$ de $\mathrm{P}_{2} \mathrm{O}_{5}$ na forma de superfosfato simples aplicado na linha de plantio. As adubações, nitrogenada e potássica, ocorreram após o completo estabelecimento das plantas, em quantidades equivalentes a $200 \mathrm{~kg} \mathrm{ha}^{-1}$ de $\mathrm{N}$, aplicados na forma de ureia e parcelados em quatro aplicações a lanço ao longo do período experimental e $40 \mathrm{~kg} \mathrm{ha}^{-1}$ de $\mathrm{K}_{2} \mathrm{O}$, aplicados na forma de cloreto de potássio, em aplicação única e a lanço, concomitantemente à primeira aplicação de nitrogênio.

A área experimental foi estabelecida com dois cultivares de Panicum maximum Jacq. (Mombaça e Aruana), um cultivar híbrido de $P$. maximum Jacq. e $P$. infestum BRA-7102 (Massai), dois cultivares de Brachiaria brizantha (A. Rich.) Stapf (Marandu e Xaraés) e com os capins gordura (Melinis minutiflora Beauv.) e jaraguá (Hyparrhenia rufa (Nees) Stapf.). Estas foram semeadas em bandejas

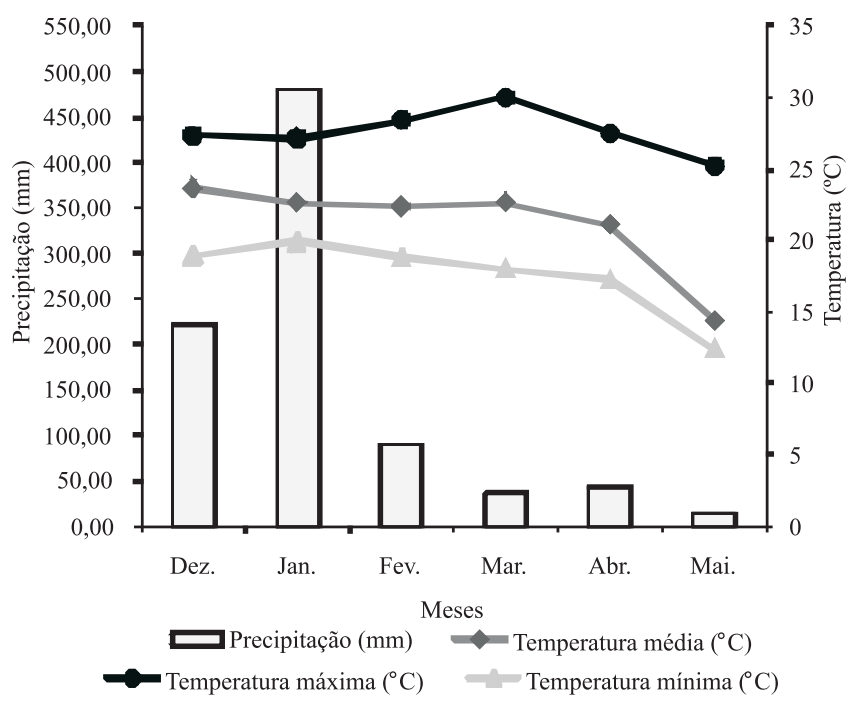

Figura 1 - Médias mensais das temperaturas máxima, média e mínima e da precipitação pluvial ao longo do período experimental de dezembro/2006 a maio/2007. 
plásticas contendo substrato orgânico, as quais foram mantidas em casa de vegetação, sob irrigação, até o momento da transplantação para o campo. A área experimental foi submetida à aração e gradagem, seguida do cultivo com enxada rotativa. Em seguida, foram preparadas as parcelas $(1,00 \mathrm{~m} \times 1,00 \mathrm{~m})$ para a transplantação das mudas, realizada em 28/11/2006.

As gramíneas foram alocadas nas parcelas experimentais, utilizando-se delineamento de blocos completos casualizados, com três repetições, totalizando 21 unidades experimentais. A utilização de blocos casualizados se deve ao fato de a área experimental ter sido alocada em terreno declivoso. Cada unidade experimental possuía quatro linhas espaçadas de 0,20 m e, em cada linha, foram transplantadas seis plantas espaçadas de $0,15 \mathrm{~m}$, totalizando 24 plantas por unidade experimental.

O experimento iniciou-se no dia 12/12/2006, após o estabelecimento das gramíneas nas unidades experimentais. Por se tratar de experimento cujos tratamentos corresponderam a cultivares e, ou, espécies de plantas forrageiras de morfologia e hábitos de crescimento contrastantes e, portanto, de exigências de manejo da desfolhação diferentes, optou-se por realizar as avaliações sob condições de crescimento livre, como forma de padronização das análises. Nessa condição, todas as forrageiras foram avaliadas durante o estádio vegetativo até o ponto em que $50 \%$ ou mais dos perfilhos se encontravam com inflorescências visíveis. Para isso, procedeu-se à análise visual das parcelas. Assim, o período experimental estendeu-se até 25/05/2007, totalizando 164 dias de avaliações.

As variáveis morfogênicas e estruturais foram avaliadas utilizando-se perfilhos de duas touceiras marcadas aleatoriamente por parcela, as quais foram monitoradas duas vezes por semana para aferição das taxas de aparecimento e alongamento foliar, alongamento de colmos e senescência foliar. Com o aparecimento da inflorescência no perfilho monitorado, um novo perfilho foi marcado, com o objetivo de prosseguir com a avaliação do crescimento e do aparecimento de novas folhas até o fim do período experimental. Para tanto, escolheu-se um perfilho que estivesse em estádio vegetativo e pertencesse à mesma touceira do perfilho anterior. Entretanto, o perfilho em estádio reprodutivo continuou a ser monitorado para avaliação da taxa de senescência das folhas nele existentes (Silveira et al., 2010). Nessa situação, o número de perfilhos monitorados foi crescente.

Os perfilhos originalmente marcados, bem como os perfilhos aéreos que surgiram durante o período experimental, foram avaliados com as seguintes características: (a) comprimento do limbo foliar e (b) classificado como folha em expansão, expandida, senescente ou morta. As folhas foram classificadas como em expansão quando sua lígula não se encontrava exposta; expandidas quando a lígula estivesse visível e/ou cessasse o seu crescimento (fato que foi considerado após duas avaliações consecutivas com variação nula no comprimento do limbo foliar); senescentes quando parte do limbo foliar apresentasse sinais de senescência (amarelecimento e/ou necrosamento em qualquer região do limbo foliar); e mortas quando mais de $50 \%$ do limbo foliar se encontrava comprometido pela senescência.

O comprimento das folhas foi medido de acordo com seu estádio de desenvolvimento. Para as folhas expandidas, o comprimento foi medido da ponta da folha até sua lígula. No caso de folhas em expansão, o mesmo procedimento foi adotado, porém considerando-se a lígula da última folha expandida como referencial de medida. Para as folhas em senescência, ao invés da ponta da folha, foi considerado o ponto até onde o processo de senescência, ou seja, o amarelecimento e/ou necrosamento da parte verde do limbo foliar avançou. Para mensuração do alongamento do colmo, foi considerada a distância do solo (ou do ponto de inserção, no caso de perfilhos aéreos) até a última lígula completamente expandida.

Com base nos dados de campo, foram calculadas as taxas de aparecimento (folhas.perfilho ${ }^{-1} \cdot \mathrm{dia}^{-1}$ ), alongamento (cm.perfilho ${ }^{-1} \cdot \mathrm{dia}^{-1}$ ) e senescência de folhas (cm.perfilho ${ }^{-1}$. $\mathrm{dia}^{-1}$ ), alongamento de colmos (cm.perfilho-1 dia $^{-1}$ ), número de folhas vivas (folhas.perfilho-1 ${ }^{-1}$ ), duração de vida da folha (dias) e comprimento final da lâmina foliar (cm).

Para a avaliação do perfilhamento, assim como das respectivas taxas de aparecimento e morte de perfilhos, duas touceiras por parcela foram marcadas aleatoriamente. Em uma primeira avaliação, todos os perfilhos existentes em cada touceira foram marcados com arame revestido de plástico de determinada cor, contados e classificados em basais ou aéreos. A cada nova avaliação, realizada consistentemente a cada 30 dias, todos os perfilhos marcados existentes eram recontados; novos perfilhos marcados com uma cor diferente da utilizada nas marcações anteriores; e os arames dos perfilhos mortos recolhidos, para sua contabilização (Carvalho et al., 2000). Foram considerados mortos os perfilhos desaparecidos e aqueles secos ou em estádio avançado de senescência. Com base nas contagens, foram calculadas as taxas de aparecimento: perfilhos aéreos e basilares, o que resultou na taxa de aparecimento total de perfilhos, e as taxas de mortalidade: perfilhos aéreos e basilares, o que resultou na taxa de mortalidade total de perfilhos. 
Os resultados referentes às características morfogênicas e estruturais e às taxas de aparecimento e morte de perfilhos foram submetidos à análise de fatores (factor analysis), empregando-se o método Varimax de rotação e ortogonalização de fatores, por intermédio do pacote estatístico SAS (Statistical Analysis System, versão 9.0). Foram adotadas como critérios de seleção de fatores as cargas fatoriais e a fração retida da variação total (comunalidade). Esse método tem como função principal descrever, se possível, as relações de co-variância entre muitas variáveis, com base em um pequeno número de quantidades aleatórias, não observáveis, chamadas fatores (Johnson \& Wichern, 1998). Após a obtenção dos escores fatoriais, estes foram utilizados como base para realização de análise multivariada de agrupamento por otimização, segundo o método de Tocher (Cruz \& Regazzi, 1997). No método de otimização proposto por Tocher, é adotado o critério de manter a distância média intragrupos sempre inferior a qualquer distância intergrupos (Rao, 1952). Foi adotada a distância euclidiana média como medida básica de dissimilaridade. Esse procedimento estatístico foi realizado por intermédio do SAEG (Sistema para Análises Estatísticas e Genéticas, versão 8.0).

As variáveis foram avaliadas em dois diferentes grupos correspondentes às características de perfilhos basilares e aéreos. A análise foi realizada em subconjuntos de dados correspondentes às épocas de verão, compreendendo as informações tomadas entre 12 de dezembro de 2006 e 20 de março de 2007; e outono, entre21 de março e 25 de maio de 2007.

\section{Resultados e Discussão}

As variáveis avaliadas (Tabela 1) foram reduzidas a quatro fatores, os quais explicaram $80 \%$ da variação total, destacando-se valores de comunalidade acima de 50\% em todas as variáveis avaliadas (Tabela 2).

O primeiro fator correlacionou-se, de maneira positiva, com as variáveis taxa de aparecimento de folhas, taxa de alongamento foliar, número de folhas vivas, taxa de aparecimento de perfilho basilar e taxa de aparecimento total de perfilhos. Trata-se, portanto, de um fator associado ao desenvolvimento de massa. O segundo fator correlacionouse positivamente com as variáveis relativas à taxa de mortalidade de perfilhos aéreos, taxa de mortalidade de perfilhos basilares e taxa de mortalidade total de perfilhos, indicando que esse fator está altamente relacionado com a mortalidade de perfilhos, razão pela qual essa foi a denominação dada a esse fator. Já o terceiro fator correlacionou positivamente com a taxa de alongamento foliar e o

Tabela 1 - Média das variáveis morfogênicas e estruturais de perfilhos basilares das sete gramíneas avaliadas nos períodos de verão e outono

\begin{tabular}{|c|c|c|c|c|c|c|c|}
\hline \multirow[t]{2}{*}{ Variável } & \multicolumn{7}{|c|}{ Gramínea } \\
\hline & Mombaça & Gordura & Xaraés & Jaraguá & Aruana & Marandu & Massai \\
\hline & & & Verão & & & & \\
\hline Taxa de aparecimento de folhas & 0,0890 & 0,1504 & 0,0823 & 0,1813 & 0,0776 & 0,0663 & 0,0907 \\
\hline Taxa de alongamento foliar & 5,6467 & 2,1783 & 4,5617 & 9,8450 & 2,0803 & 2,0425 & 3,0917 \\
\hline Número de folhas vivas & 5,3333 & 5,1111 & 6,3333 & 7,5000 & 1,6944 & 4,5833 & 4,8333 \\
\hline Duração de vida da folha & 60,4617 & 39,7683 & 76,7900 & 40,8217 & 16,4450 & 78,2208 & 52,3133 \\
\hline Taxa de senescência foliar & 0,1810 & 0,3024 & 0,1093 & 0,2969 & 0,1107 & 0,0871 & 0,1753 \\
\hline Comprimento final da lâmina foliar & 52,4217 & 14,3411 & 47,7900 & 49,0533 & 25,5233 & 29,8325 & 32,9667 \\
\hline Taxa de alongamento de colmo & 0,2933 & 0,5794 & 0,3817 & 0,3900 & 1,1329 & 0,7817 & 0,0733 \\
\hline Taxa de aparecimento de perfilhos aéreos & 0,0000 & 0,0425 & 0,0000 & 0,0000 & 0,0325 & 0,0000 & 0,0000 \\
\hline Taxa de aparecimento de perfilhos basilares & 0,0246 & 0,1162 & 0,0468 & 0,1865 & 0,0210 & 0,0471 & 0,0842 \\
\hline Taxa de aparecimento total de perfilhos & 0,0246 & 0,1933 & 0,0468 & 0,1865 & 0,0585 & 0,0484 & 0,0842 \\
\hline Taxa de mortalidade de pefilhos aéreos & 0,0000 & 0,0010 & 0,0000 & 0,0000 & 0,0005 & 0,0000 & 0,0000 \\
\hline Taxa de mortalidade de perfilhos basilares & 0,0000 & 0,0003 & 0,0000 & 0,0012 & 0,0049 & 0,0001 & 0,0002 \\
\hline Taxa de mortalidade total de perfilhos & 0,0000 & 0,0008 & 0,0000 & 0,0012 & 0,0025 & 0,0001 & 0,0002 \\
\hline & & & Outono & & & & \\
\hline Taxa de aparecimento de folhas & 0,0441 & 0,0715 & 0,0382 & 0,1088 & 0,0406 & 0,0235 & 0,0424 \\
\hline Taxa de alongamento foliar & 1,4078 & 0,3797 & 0,6150 & 1,6015 & 1,1615 & 0,3981 & 0,5142 \\
\hline Número de folhas vivas & 3,8167 & 2,0833 & 2,9167 & 2,6167 & 2,7500 & 3,1444 & 3,9048 \\
\hline Duração de vida da folha & 75,1317 & 23,6667 & 68,4017 & 23,8828 & 48,6500 & 69,1556 & 80,3571 \\
\hline Taxa de senescência foliar & 0,0946 & 0,1157 & 0,1224 & 0,3063 & 0,0861 & 0,1651 & 0,1041 \\
\hline Comprimento final da lâmina foliar & 39,9918 & 6,7914 & 28,9608 & 35,3600 & 24,9265 & 22,4757 & 28,0732 \\
\hline Taxa de alongamento de colmo & 0,6032 & 0,2650 & 0,7192 & 0,7972 & 0,3972 & 0,5142 & 0,4710 \\
\hline Taxa de aparecimento de perfilhos aéreos & 0,0000 & 0,0135 & 0,0000 & 0,0000 & 0,0178 & 0,0518 & 0,0000 \\
\hline Taxa de aparecimento de perfilhos basilares & 0,0049 & 0,0022 & 0,0035 & 0,0000 & 0,0255 & 0,0026 & 0,0014 \\
\hline Taxa de aparecimento total de perfilhos & 0,0049 & 0,0100 & 0,0035 & 0,0000 & 0,0135 & 0,0130 & 0,0016 \\
\hline Taxa de mortalidade de pefilhos aéreos & 0,0000 & 0,0086 & 0,0000 & 0,0000 & 0,0107 & 0,0007 & 0,0000 \\
\hline Taxa de mortalidade de perfilhos basilares & 0,0031 & 0,0066 & 0,0004 & 0,0054 & 0,0099 & 0,0055 & 0,0026 \\
\hline Taxa de mortalidade total de perfilhos & 0,0031 & 0,0081 & 0,0004 & 0,0054 & 0,0099 & 0,0047 & 0,0026 \\
\hline
\end{tabular}


Tabela 2 - Cargas fatoriais e comunalidades das características morfogênicas e de perfilhamento basilar

\begin{tabular}{lcccc}
\hline Variável & \multicolumn{3}{c}{ Fator } \\
\cline { 2 - 4 } & $\begin{array}{c}\text { Desenvolvimento } \\
\text { de massa }\end{array}$ & $\begin{array}{c}\text { Mortalidade } \\
\text { de perfilhos }\end{array}$ & $\begin{array}{c}\text { Estádio de } \\
\text { desenvolvimento }\end{array}$ & $\begin{array}{c}\text { Longevidade } \\
\text { foliar }\end{array}$ \\
\hline Taxa de aparecimento das folhas & 0,7999 & $-0,0949$ & 0,0651 & 0,4314 \\
Taxa de alongamento foliar & 0,7208 & $-0,1244$ & 0,5540 & 0,8392 \\
Número de folhas vivas & 0,7664 & $-0,2277$ & 0,4043 & $-0,2512$ \\
Duração de vida da folha & $-0,0533$ & $-0,2501$ & 0,2460 & $-0,7713$ \\
Taxa de senecência foliar & 0,2919 & $-0,0869$ & 0,0568 & 0,8639 \\
Comprimento final da lâmina foliar & 0,1527 & $-0,3350$ & 0,8509 & 0,7208 \\
Taxa de alongamento de colmo & $-0,2662$ & $-0,4931$ & $-0,4315$ & 0,0582 \\
Taxa de aparecimento de perfilhos aéreos & 0,0720 & 0,1295 & $-0,6746$ & 0,0008 \\
Taxa de aparecimento de perfilhos basilares & 0,9387 & $-0,0931$ & 0,0699 & 0,2669 \\
Taxa de aparecimento total de perfilhos & 0,9037 & $-0,1706$ & $-0,1868$ & 0,8629 \\
Taxa de mortalidade de perfilhos aéreos & $-0,0701$ & 0,8837 & $-0,2488$ & 0,1690 \\
Taxa de mortalidade de perfilhos basilares & $-0,3622$ & 0,7504 & $-0,2106$ & 0,1375 \\
Taxa de mortalidade total de perfilhos & $-0,3285$ & 0,8654 & $-0,1799$ & $-0,1084$ \\
Comunalidade & 3,8761 & 2,6493 & 2,0820 & 0,92225 \\
Variação explicada & 0,4000 & 0,2100 & 0,1100 & 0,8996 \\
\hline
\end{tabular}

comprimento final da lâmina foliar, característico do estádio vegetativo da planta, sendo que o comprimento final da lâmina foliar também possui associação com o estádio reprodutivo da planta, uma vez que, em todos os estádios, as plantas têm determinado comprimento de folhas e, momentos antes do florescimento, a taxa de alongamento de folhas ocorre, embora as folhas sejam menores. Além disso, esse fator correlacionou-se de forma negativa com a taxa de alongamento de colmo e a taxa de aparecimento de perfilhos aéreos, característico do estádio reprodutivo. Assim, o terceiro fator foi denominado estádio de desenvolvimento. O quarto fator, por sua vez, correlacionou-se negativamente com a duração de vida da folha e positivamente com a taxa de senescência foliar, indicando longevidade foliar.

Com base nos resultados dos fatores, foi realizado o agrupamento das gramíneas, o que possibilitou separá-los em três grupos no período referente ao verão (Tabela 3). O grupo I, formado pelos capins xaraés, massai, mombaça e marandu; o grupo II, pelos capins gordura e aruana; e o grupo III, pelo capim-jaraguá. Os fatores, estádio de desenvolvimento e longevidade foliar tiveram as maiores participações (38,1\% e 28,6\%, respectivamente) na determinação desses grupos.
O fator desenvolvimento de massa apresentou escore positivo para todos os grupos (Tabela 3). Contudo, os padrões de desenvolvimento de massa dos grupos de gramíneas diferiram entre si quanto à forma de utilização dos recursos disponíveis. As gramíneas do grupo I priorizaram o desenvolvimento de massa, por meio da taxa de alongamento foliar e número de folhas vivas (Tabela 1), com valores elevados para essas variáveis, geralmente plantas que respondem com alta taxa de alongamento foliar, consequentemente possuem folhas grandes (Nabinger \& Pontes, 2001), fato observado para as gramíneas deste grupo. A gramínea do grupo III fez uso de todos os recursos disponíveis para o desenvolvimento de massa, com valores elevados para todas as variáveis (Tabela 1), principalmente para a taxa de alongamento foliar, uma importante característica morfogênica no estudo da dinâmica de acúmulo de forragem, por possuir alta correlação com a produção de massa do pasto (Horst et al., 1978).

As gramíneas que compõem o grupo II apresentaram valores intermediários para todas as variáveis. Os valores foram mais expressivos para a taxa de aparecimento de perfilhos basilares e a taxa de aparecimento total de perfilhos (Tabela1), promovendo desenvolvimento de

Tabela 3 - Grupos de gramíneas avaliadas no período de verão, médias das variáveis em cada grupo, contribuição das variáveis para discriminação dos grupos e as distâncias média intragrupos

\begin{tabular}{lccc}
\hline Item & \multicolumn{1}{c}{ Contribuições dos Fatores } \\
\cline { 2 - 3 } & I & II & III \\
\hline Distância média intragrupo & 1,1046 & - & - \\
Desenvolvimento de massa & 0,1675 & 1,2059 & 2,3421 \\
Mortalidade de perfilhos & $-0,5143$ & 0,5271 & 0,1191 \\
Estádio de desenvolvimento & $-0,6931$ & $-0,6031$ & 1,0651 \\
Longevidade foliar & $-0,4820$ & 0,6980 & 0,8472 \\
\hline
\end{tabular}

*Grupo I - Xaraés, Massai, Mombaça e Marandu; Grupo II - Gordura e Aruana; Grupo III - Jaraguá. 
massa moderado. Em casos que o cultivar apresenta baixo potencial de acúmulo de folhas por intermédio do alongamento foliar, esse faz uso de recursos como aparecimento foliar ou de perfilhos, como foi o caso das gramíneas do grupo II, fato que corrobora a observação realizada por Silveira et al. (2007) para a B. humidicola cv. Tupi. Assim, pode se inferir que o capim-jaraguá, que compõe o grupo III, respondeu com desenvolvimento de massa mais rápido em relação aos grupos I e II, uma vez que o grupo III registrou maior valor de escore para o fator desenvolvimento de massa (Tabela 3).

Foi observado, para o fator mortalidade de perfilhos, contraste entre os grupos I e II com o grupo III (Tabela 3). No entanto, pode-se dizer que o escore registrado pelo grupo II não é tão expressivo, como foi observado antes na gramínea que o compõe, sendo causado pelo método de estudo utilizado, pois todas as gramíneas tiveram valores baixos para mortalidade de perfilhos no período de verão. O padrão de mortalidade de perflhos das gramíneas do grupo I, quanto ao fator mortalidade de perfilhos associado ao desenvolvimento de massa, permite inferir que esses indivíduos apresentam baixa renovação da população de perfilhos. Silveira et al. (2009), em trabalho análogo a esse, observaram o mesmo padrão para os capins mombaça, xaraés, marandu e massai, e caracterizaram-nos como gramíneas com perfilhos de maior longevidade.

No grupo II, o capim-aruana destacou-se pela taxa de mortalidade de perfilhos, que foi a mais elevada, possivelmente em decorrência do florescimento precoce registrado para essa gramínea. Quando não ocorre a substituição adequada dos perfilhos mortos por novos perfilhos, a comunidade vegetal pode entrar em colapso. Logo, entre as gramíneas estudadas, o capim-aruana seria o que requer maior cuidado quanto às estratégias de uso na tentativa de manter o mínimo necessário de perfilhos para assegurar a persistência dessa planta na área.

No fator estádio de desenvolvimento, também foi observado contraste entre os grupos I e II com o grupo III (Tabela 3). Durante o período de verão, não ocorreu florescimento nas gramíneas do grupo I, contribuindo para valores significativos de taxa de alongamento foliar e comprimento final da lâmina foliar, além da ausência de perfilhos aéreos, o que caracteriza o grupo I com escore negativo. No grupo II também foi registrado escore negativo, contudo as gramíneas desse grupo tiveram perfilhos aéreos e elevada taxa de alongamento de colmo, além de baixa taxa de alongamento foliar e comprimento final da lâmina foliar, caracterizando precocidade no florescimento, no caso do capim-aruana. Já para o capim-gordura, pertencente ao grupo II, não foi observado florescimento precoce, sendo característico nessa gramínea o florescimento no meio da estação do outono. Com isso, pode-se atribuir o padrão de escore negativo nesse grupo principalmente à elevada taxa de aparecimento de perfilhos aéreoos, registrada pelo capim-gordura. O grupo III foi caracterizado por escore positivo (Tabela 3), com valores elevados para taxa de alongamento foliar e comprimento final da lâmina foliar e moderados para taxa de alongamento de colmo (Tabela 1), bem como ausência de perfilhamento aéreo, além de florescimento tardio. Já nas gramíneas do grupo II, em particular o capim-aruana com o florescimento precoce, o acelerado desenvolvimento de massa do grupo III afetam a estrutura do dossel e o valor nutritivo da forragem, podendo implicar em redução no consumo voluntário animal.

A duração de vida da folha no perfilho é uma característica genética, com valores relativamente constantes em condições de manejo (Davies, 1974), que podem ser influenciadas por fatores ambientais. O contraste observado no fator longevidade foliar foi estabelecido entre o grupo I e os grupos II e III (Tabela 3). Nas gramíneas dos grupos II e III, foram observadas elevadas taxas de senescência foliar, implicando em menor longevidade foliar, que pode ser atribuído ao maior fluxo de tecido registrado por essas gramíneas, uma vez que as mesmas apresentaram taxa de aparecimento de folhas relativamente maiores que as gramíneas do grupo I. As gramíneas do grupo I tiveram elevada duração de vida das folhas e baixa taxa de senescência foliar, possivelmente devido ao maior tempo que as gramíneas deste grupo levaram alongando folhas em detrimento da taxa de aparecimento das folhas. Com isso, infere-se que as gramíneas dos grupos II e III requerem maiores exigências quanto às estratégias de desfolhação, como forma de assegurar elevada eficiência de colheita, reduzindo as perdas por senescência em relação àquelas do grupo I.

O agrupamento realizado no período de avaliação, outono, permitiu a formação de três grupos (Tabela 4): o grupo I formado pelos capins mombaça, massai, xaraés, marandu e gordura; o grupo II pelo capim-jaraguá; e o grupo III pelo capim-aruana. Os fatores estádio de desenvolvimento, longevidade foliar e mortalidade de perfilhos tiveram maiores contribuições (33,3; 28,6 e 23,8\%, respectivamente) para determinação dos grupos. Possivelmente, o aumento percentual da participação do fator mortalidade de perfilhos na formação dos grupos, tenha sido o responsável pela mudança de grupo do capim-gordura e o isolamento do capim-aruana no grupo III neste período, em relação ao período de verão. 
Tabela 4 - Grupos de gramíneas avaliadas no período de outono, médias das variáveis em cada grupo, contribuição das variáveis para discriminação dos grupos e as distâncias média intragrupos

\begin{tabular}{|c|c|c|c|c|}
\hline \multirow[t]{2}{*}{ Item } & \multicolumn{3}{|c|}{ Grupo* } & \multirow[t]{2}{*}{ Contribuição dos fatores } \\
\hline & I & II & III & \\
\hline Distância média intragrupo & 1,2054 & - & - & - \\
\hline Desenvolvimento de massa & $-0,6518$ & $-1,0614$ & $-0,2451$ & 14,3 \\
\hline Mortalidade de perfilhos & 0,1039 & $-0,2217$ & 2,3731 & 23,8 \\
\hline Estádio de desenvolvimento & $-0,1995$ & 0,4207 & $-0,1274$ & 33,3 \\
\hline Longevidade foliar & $-0,3788$ & 1,9000 & $-0,4791$ & 28,6 \\
\hline
\end{tabular}

Houve mudanças nos escores para todos os fatores no período de outono, devido ao efeito da redução da temperatura, precipitação (Figura 1) e fotoperíodo, uma vez que as características morfogênicas das gramíneas são afetadas por fatores ambientais (Lemaire \& Chapman, 1996), alterando consequentemente as características estruturais, que por sua vez promovem redução no acúmulo de massa, independentemente de serem relacionadas ao desenvolvimento e tamanho de perfilhos individuais (alongamento de folhas e número de folhas por perfilho - acúmulo de massa por investimento em massa por perfilho) ou com o desenvolvimento e tamanho da população de perfilhos e renovação de folhas (perfilhamento e aparecimento de folhas - acúmulo de massa por investimento em população) (Rodrigues et al., 2011).

O fator desenvolvimento de massa no outono, ao contrário do verão, teve escores negativos em todos os grupos (Tabela 4). O grupo I teve padrão desenvolvimento de massa moderado, como consequência do equilíbrio entre os recursos utilizados pelas gramíneas, pois os capins mombaça, massai e xaraés registraram baixas taxas de aparecimento de perfilhos basilares e taxas de aparecimento total de perfilhos e valores maiores para taxa de alongamento foliar, enquanto os capins marandu e gordura perfilharam mais, principalmente perfilhos aéreos, que contribuíram significativamente para a taxa de aparecimento total de perfilhos, no entanto, com reduzida taxa de alongamento foliar (Tabela 1). Da Silva \& Sbrissia (2010) argumentaram que pastos de capim-marandu aumentam a densidade populacional de perfilhos aéreos (axilares) no período de outono/inverno, como forma de compensar a redução na taxa de alongamento foliar e assim aumentar a ocupação de sítios e sua área foliar. De maneira geral a taxa de alongamento foliar reduziu para as gramíneas de todos os grupos, devido a reduções em temperatura e precipitação (Figura 1), afetando o alongamento foliar, uma vez que a divisão e principalmente o crescimento das células são processos extremamente sensíveis ao turgor celular (Ludlow \& Ng, 1977). No grupo II, o desenvolvimento de massa foi lento, pois foi priorizado pelas taxas de alongamento foliar e número de folhas vivas, não havendo perfilhamento nesse período para o capimjaraguá. Já no grupo III o desenvolvimento de massa teve maior participação das taxas de alongamento foliar, aparecimento de perfilhos basilares e aparecimento total de perfilhos, promovendo fluxo mais rápido no desenvolvimento de massa.

A temperatura influencia a dinâmica de acúmulo de massa à medida que a resposta da taxa de alongamento foliar à variação em temperatura é imediata (Peacock, 1975; Lemaire \& Agnusdei, 2000), de tal forma que a produção de tecidos segue exatamente as variações térmicas sazonais. Além da taxa de alongamento foliar, a taxa de aparecimento das folhas também é afetada pelo efeito sinérgico da temperatura e umidade, pois a taxa de aparecimento das folhas é influenciada por fatores do meio. A resposta da taxa de aparecimento das folhas a qualquer variação de temperatura percebida pelo meristema apical é imediata (Peacock, 1975), e, à medida que a temperatura aumenta, a taxa de aparecimento das folhas responde de forma positiva e vice-versa. Com isso, pode-se dizer que a gramínea do grupo III apresenta desenvolvimento de massa mais acelerado no período de outono, em relação às gramíneas dos grupos I e II, podendo mostrar maior exigência quanto à estratégia de desfolhação.

O fator mortalidade de perfilhos registrou padrão contrastante entre o grupo II com os grupos I e III (Tabela 4). O grupo III foi o mais afetado com a mudança na estação do ano, principalmente com a mortalidade de perfilhos aéreos, responsável pelo escore positivo registrado pelo grupo. De acordo com Silveira et al. (2010), o perfilhamento é influenciado por vários fatores relacionados ao ambiente e ao manejo adotado. Logo, a forma como determinada espécie e/ou cultivar demonstra sua capacidade de perfilhar serve como indicativo de resposta adaptativa a determinada situação ou região. Por exemplo, quanto maior a renovação de perfilhos em determinado cultivar, maior será a renovação de tecidos e mais exigente será essa planta em termos de fertilidade do solo e manejo da desfolhação. Possivelmente o padrão demonstrado pelo capim-aruana, inerente ao desenvolvimento de massa (com valores altos para 
aparecimento de perfilhos) e à mortalidade de perfilhos, tenha sido o responsável pelo seu isolamento no grupo III, apresentando maior renovação de tecido no outono.

A mortalidade de perfilhos no grupo II ocorreu em menor intensidade, consequência das reduzidas taxas de mortalidade de perfilhos basilares e mortalidade total de perfilhos do capim-jaraguá, não havendo contribuição da taxa de mortalidade de perfilhos aéreos, uma vez que a gramínea não teve a categoria de perfilhos supracitada. O não perfilhamento do capim-jaraguá talvez tenha influenciado na maior longevidade de perfilhos desta gramínea, como garantia de manutenção na área cultivada, já que a densidade populacional de perfilhos em comunidades de plantas forrageiras é função do equilíbrio entre as taxas de aparecimento e morte de perfilhos (Lemaire \& Chapman, 1996). Já o grupo I apresentou mortalidade de perfilhos moderada, tendo em geral equilíbrio entre as taxas de mortalidade de perfilhos das gramíneas que compõem o grupo.

O estádio de desenvolvimento, nos grupos I e III, teve padrão semelhante, contrastando com o grupo II (Tabela 4). No entanto, no grupo I, de forma geral, foram observados valores moderados para taxa de alongamento foliar, comprimento final da lâmina foliar e a taxa de alongamento de colmo e valores baixos para taxa de aparecimento de perfilhos aéreos, pois somente os capins marandu e gordura desenvolveram perfilhos aéreos. A maioria das gramíneas do grupo I exibiu inflorescência no final do experimento, exceto o capim-marandu, que emitiu florescimento no início do outono. Já o grupo III registrou elevadas taxa de alongamento foliar e taxa de aparecimento de perfilhos aéreos, com valores moderados para comprimento final da lâmina foliar e baixa taxa de alongamento de colmo. Esse padrão se deve ao fato de a gramínea desse grupo ter florescido precocemente. Logo, a maioria dos perfilhos basilares encontrava-se em estádio reprodutivo no outono, proporcionando valores altos de taxa de aparecimento de perfilhos aéreos em relação às demais gramíneas. O grupo II registrou valores elevados para taxa de alongamento foliar, comprimento final da lâmina foliar e taxa de alongamento e ausência de perfilhos aéreos, implicando em capim de folhas e colmos grandes e podendo exigir maior intensidade de desfolhação para controle da estrutura.

A senescência de folhas é um processo que implica na perda de atividade metabólica (Patterson \& Moss, 1979) e pode ser influenciada pelo ambiente, estádio de desenvolvimento da planta e características inerentes à própria espécie forrageira (Hardwick \& Woolhouse, 1967).
A gramínea do grupo II registrou elevada taxa de senescência foliar e baixa duração de vida das folhas, implicando menor longevidade foliar. Provavelmente esse efeito seja função da estacionalidade de perfilhamento observada no capim-jaraguá no outono, com isso resultando em população de perfilhos velhos nesse período. O grupo II registrou padrão contrastante com os grupos I e III, em que foi observada similaridade para o fator longevidade foliar. Entretanto, as gramíneas dos grupos I e III utilizaram recursos diferentes para obter escores fatoriais semelhantes. As gramíneas do grupo I registraram elevada duração de vida das folhas e valores moderados para taxa de senescência foliar, enquanto a gramínea do grupo II teve baixa taxa de senescência foliar e valores moderados de duração de vida das folhas, com ambos os grupos mostrando maior longevidade foliar que o grupo II. A maior longevidade foliar geralmente pode estar associada a mecanismos de economia de recursos em condições de adversidade climática, momento que ocorre redução no alongamento foliar e na densidade populacional de perfilhos (Da Silva \& Sbrissia, 2010).

O padrão observado nas gramíneas nos períodos de verão e outono revela que as mesmas se utilizam dos recursos morfogenéticos e estruturais, de forma funcional e guardando suas devidas magnitudes entre épocas do ano, para potencializar o fluxo de tecidos (Rodrigues et al., 2009), independentemente do gênero ou da espécie, porém apresentando similaridades no processo que permitem o seu agrupamento.

\section{Conclusões}

O agrupamento funcional apresenta elevado potencial de utilização para a avaliação de plantas forrageiras, permitindo melhor compreensão do padrão apresentado pelas gramíneas em relação ao crescimento e desenvolvimento.

\section{Referências}

BROWN, J.S. Principal component and cluster analysis of cotton cultivar variability across the U.S. cotton belt. Crop Science, v.31, p.915-922, 1991.

CARVALHO, C.A.B.; Da SILVA, S.C.; CARNEVALLI, R.A. et al. Perfilhamento e acúmulo de forragem em pastagens de Florakirk (Cynodon spp.) manejadas em quatro alturas de pasto. Boletim da Indústria Animal, v.57, n.1, p.39-51, 2000.

COMISSÃO DE FERTILIDADE DO SOLO DO ESTADO DE MINAS GERAIS CFSEMG. Recomendações para o uso de corretivos e fertilizantes em Minas Gerais: $5^{\mathrm{a}}$ Aproximação. RIBEIRO, A.C. et al. (Ed.). Viçosa, MG: UFV, 1999. 359p.

CRUZ, C.D.; REGAZZI, A.J. Modelos biométricos aplicados ao melhoramento genético. 2.ed. Viçosa, MG: Editora UFV, 1997. 390p. 
DA SILVA, S.C; SBRISSIA, A.F. Análise de componentes principais entre características morfogênicas e estruturais em capimmarandu sob lotação contínua. Ciência Rural, v.40, n.3, p.690-693, 2010.

DAVIES, A. Leaf tissue remaining after cutting and regrowth in perennial ryegrass. Journal of Agriculture Science, v.82, p.65-172, 1974.

DIAS-FILHO, M.B.; SIMÃO NETO, M.S.; SERRÃO, E.A.S. Adaptação de acessos de Centrosema acutifolium, Desmodium ovalifolium e Pueraria phaseoloides na Amazonia Oriental do Brasil. Pasturas Tropicales, v.14, n.18, p.18-23, 1992.

DIAS-FILHO, M.B.; SIMÃO NETO, M.S.; SERRÃO, E.A.S. Cluster analysis for assessing the agronomic adaptation of Panicum maximum Jacq. accessions. Pesquisa Agropecuária Brasileira, v.29, n.10, p.1509-1516, 1994.

EMPRESA BRASILEIRA DE PESQUISA AGROPECUÁRIA EMBRAPA. Centro Nacional e Pesquisa em Solos. Sistema brasileiro de classificação de solos. Brasília: Embrapa-SPI; Rio de Janeiro: Embrapa-Solos, 2006. 306p.

HARDWICK, K.; WOOLHOUSE, H.W. Foliar senescence in Perilla frutescens (L.) Britt. New Phytology, v.66, p.545-552, 1967.

HORST, G.L.; NELSON, C.J.; ASAY, K.H. Relationship of leaf elongation to forage yield of tall fescue genotypes. Crop Science, v.18, p.715-719, 1978.

JOHNSON, R.A.; WICHERN, D.W. Applied multivariate statistical analysis. 4.ed. New Jersey: Prentice-Hall, 1998. 816p.

JOLLIFFE, I.T.; ALLEN, O.B.; CHRISTIE, B.R. Comparison of variety mens using cluster analysis and dendrograms. Experimental Agriculture, v.25, p.259-269, 1989.

LEMAIRE, G., AGNUSDEI, M. Leaf tissue turn-over and efficiency of herbage utilization. In: LEMAIRE, G.; HODGSON, J.; MORAES, A. et al. (Eds.). Grassland ecophysiology and grazing ecology. Wallingford: CAB International. 2000. p.265-288.

LEMAIRE, G.; CHAPMAN, D.F. Tissue flows in grazed plant communities. In: HODGSON, J.; ILLIUS, A.W. (Eds.). The ecology and management of grazing systems. Oxon: $\mathrm{CAB}$ International, 1996. p.3-36.

LUDLOW, M.M.; NG, T.T. Leaf elongation rate in Panicum maximum var. trichoglume following removal of water stress. Australian Journal of Plant Physiology, v.42, p.263-272, 1977.

MURPHY, J.P.; COX, T.S.; RODGERS, D.M. Cluster analysis of red winter wheat cultivars based unpon coefficients of parentage. Crop Science, v.26, p.672-676, 1986.

NABINGER, C.; PONTES, L.S. Morfogênese de plantas forrageiras e estrutura do pasto. In: REUNIÃO ANUAL DA SOCIDADE
BRASILEIRA DE ZOOTECNIA, 38., 2001, Piracicaba. Anais... Piracicaba: SBZ, 2001. p.755-771.

NASCIMENTO JÚNIOR, D.; GARCEZ NETO, A.F.; BARBOSA, R.A. et al. Fundamentos para o manejo de pastagens: Evolução e atualidades. In: OBEID, J.A. et al. (Eds.). SIMPÓSIO SOBRE MANEJO ESTRATÉGICO DA PASTAGEM, 1., 2002, Viçosa, mg. Anais... Viçosa, MG: Editora Suprema, 2002. p.149-196.

PATERSON, T.G.; MOSS, D.N. Senescence in field-grown wheat. Crop Science, v.19, 635-640, 1979.

PEACOCK, J.M. Temperature and leaf growth in Lolium perene. 1. The thermal microclimate: its measurement and relation to plant growth. Journal of Applied Ecology, v.12, p.115-123, 1975.

RAO, R.C. Advanced statistical methods in biometric research. New York: John Wiley, 1952. 390p.

REIS, W.P.; VELLO, N.A.; FERREIRA, D.F. et al. Associação entre coeficiente de parentesco e técnicas multivariadas como medidas de dissimilaridade genética de cultivares de trigo. Ciência e Agrotecnologia, v.23, n.2, p.258-269, 1999.

RODRIGUES, C.S.; NASCIMENTO JÚNIOR, D.; Da SILVA, S.C.; et al. Characterization of tropical forage grass development pattern through the morphogenetic and structural caracteristics. Revista Brasileira de Zootecnia, v.40, n.3, p.527-534, 2011.

RODRIGUES, C.S; SILVEIRA, M.C.T.; NASCIMENTO JÚNIOR, D. et al. Caracterização morfogênica e estrutural de quatro gramíneas forrageiras tropicais sob crescimento livre. In: REUNIÃO ANUAL DA SOCIEDADE BRASILEIRA DE ZOOTECNIA, 46., 2009, Maringá. Anais... Paraná: Sociedade Brasileira de Zootecnia. [2009]. (CD-ROM).

SILVEIRA, M.C.T.; MONTAGNER, D. B.; SOUSA, B. M. L. et al. Aparecimento de folhas e dinâmica do perfilhamento de oito cultivares de Brachiaria e dois de Panicum. In: REUNIÃO ANUAL DA SOCIEDADE BRASILEIRA DE ZOOTECNIA, 44., 2007, Jaboticabal. Anais... São Paulo: Sociedade Brasileira de Zootecnia. [2007]. (CD-ROM).

SILVEIRA, M.C.T.; NASCIMENTO JÚNIOR, D.; Da SILVA, S.C. et al. Morphogenetic and structural comparative characterization of tropical forage grass cultivars under free growth. Scientia Agrícola, v.19, n.2, p.136-142, 2010.

SILVEIRA, M.C.T.; RODRIGUES, C.S; NASCIMENTO JÚNIOR, D. et al. Aparecimento de folhas e dinâmica de perfilhamento de sete forrageiras tropicais sob crescimento livre. In: REUNIÃO ANUAL DA SOCIEDADE BRASILEIRA DE ZOOTECNIA, 46., 2009, Maringá. Anais... Maringá: Sociedade Brasileira de Zootecnia. [2009]. (CD-ROM).

WHITE, W.H. Cluster analysis for assessing sugarcane borer resitance in sugarcane line trials. Field Crops Research, v.33, p.159-168, 1993. 